\title{
Fondements et principes de la reproduction humaine (1993-1998)
}

Étienne-Émile Baulieu

\section{(2) OpenEdition \\ Journals}

Édition électronique

URL : https://journals.openedition.org/annuaire-cdf/16051

DOI : 10.4000/annuaire-cdf. 16051

ISBN : 978-2-7226-0572-5

ISSN : 2109-9227

Éditeur

Collège de France

Édition imprimée

Date de publication : 30 décembre 2020

Pagination : 625

ISBN : 978-2-7226-0516-9

ISSN : 0069-5580

\section{Référence électronique}

Étienne-Émile Baulieu, «Fondements et principes de la reproduction humaine (1993-1998) », L'annuaire du Collège de France [En ligne], 118 | 2020, mis en ligne le 01 avril 2021, consulté le 22 août 2022. URL : http://journals.openedition.org/annuaire-cdf/16051; DOI : https://doi.org/10.4000/annuaire-cdf. 16051 


\section{FONDEMENTS ET PRINCIPES DE LA REPRODUCTION HUMAINE}

(1993-1998)

\section{Étienne-Émile BAULIEU}

Membre de l'Institut (Académie des sciences), professeur émérite

Mots-clés : reproduction humaine

\section{ACTIVITÉS DE RECHERCHE}

Spécialiste des hormones stéroïdes pendant plus de 30 ans, c'est en analysant le fonctionnement de dérivés cérébraux du cholestérol que j'ai découvert les composés auxquels j'ai donné un nom de neurostéroïdes. Leur analyse et leur importance ont été évoquées chez des animaux et le cerveau de malades humains décédés [1]. Une revue en cours de publication précisera le rôle des neurostéroïdes dans le mécanisme des dépressions et des addictions humaines (N. Froger, E. Baulieu et I. Villey, en préparation).

Nous avons collaboré aux travaux sur la myélinisation du professeur Massaad et de ses collaborateurs [2].

La découverte et la mise en évidence de l'activité, en 1970, d'une protéine nerveuse enzymatique (peptidyl-prolyl isomérase : FKBP52) et son interaction avec la protéine Tau, ainsi que sa diminution cérébrale considérable au cours de la maladie d'Alzheimer (observées en 1972), restent centrales dans nos recherches sur la maladie d'Alzheimer, la plus grave de toutes les démences. L'article de référence [3] résume les travaux publiés en juin 2018 décrivant l'état actuel des observations dans ce domaine. Le travail se poursuit, en particulier pour définir un ou des dérivés de FKBP52 ayant un effet thérapeutique provoqué par son interaction avec Tau pathologique en excès.

\section{Publications}

[1] SchVerer M., LANFumey L., Baulieu E.-E., Froger N. et Villey I., « Neurosteroids: nongenomic pathways in neuroplasticity and involvement in neurological diseases », Pharmacology \& Therapeutics, vol. 191, 2018, p. 190-206, DOI : 10.1016/j.pharmthera.2018.06.011.

[2] Shackleford G., Sampathkumar N.K., Hichor M., Weill L., MefFre D., JuriceK L., Laurendeau I., Chevallier A., Ortonne N., Larousserie F., Herbin M., Bièche I., Coumoul X., Beraneck M., Baulieu E.-E., Charbonnier F., PASMAnt E. et MassaAd C., «Involvement of Aryl hydrocarbon receptor in myelination and in human nerve sheath tumorigenesis », Proceedings of the National Academy of Sciences of the United States of America, vol. 115, $\mathrm{n}^{\circ}$ 6, 2018, E1319-E1328, DOI : 10.1073/pnas.1715999115.

[3] Baulieu E.-E., «Steroids and brain, a rising bio-medical domain: a perspective », Frontiers in Endocrinology, vol. 9, 2018, DOI : 10.3389/fendo.2018.00316. 